\title{
Covid-19 y cirugía ortopédica: Revisión de la literatura y evidencias
}

\section{Covid-19 and Orthopedic Surgery: Review of the Literature and Evidence}

\author{
Karen A. Weissmann ${ }^{1,20}$ Carlos Huaiquilaf ${ }^{1}$ Marcelo Costa ${ }^{3}$ Cristian Correa ${ }^{4}$ Alan Bey ${ }^{5,6}$ \\ Luis Bahamonde M. ${ }^{1}$
}

${ }^{1}$ Departamento de Ortopedia y Traumatología, Universidad de Chile,
Santiago, Chile
${ }^{2}$ Departamento de Ortopedia y Traumatología, Universidad Católica
de Valencia San Vicente Mártir, Valencia, España
${ }^{3}$ Equipo de columna Redsalud Santiago, Santiago, Chile
${ }^{4}$ Departamento de Ortopedia y Traumatología, Universidad de la
Frontera, Temuco, Chile
${ }^{5}$ Universidad Finis Terrae, Región Metropolitana, Santiago, Chile
6 Universidad Diego Portales, Región Metropolitana, Santiago, Chile

Dirección para correspondencia Karen A. Weissmann, Departamento de Ortopedia y Traumatología, Universidad de Chile, avenida Libertador Bernardo O’Higgins 1.058, Santiago de Chile, Chile (e-mail: karenw9@gmail.com).

Rev Chil Ortop Traumatol 2021;62:57-65.

\section{Resumen \\ Palabras clave \\ - pandemia \\ - covid-19 \\ - cirugía ortopédica}

Se ha declarado una pandemia ante la propagación de un nuevo virus con alta contagiosidad, llamado síndrome respiratorio agudo severo coronavirus 2 (severe acute respiratory syndrome coronavirus 2, SARS-CoV2). El mundo ha quedado detenido ante la rápida expansión del virus, con una letalidad que en algunos países llega a 15\%. En Chile, el gobierno ha tomado medidas rápidas y agresivas que han permitido mantener la curva de contagios a un nivel que permita atender de manera adecuada a la población. Dentro de estas medidas, se contempla la suspensión de cirugías y consultas ambulatorias. Como cirujanos ortopédicos, nos hemos visto afectados por estas medidas, y existe confusión respecto a cuál es la conducta más adecuada. Quisimos hacer esta guía para resumir parte de las evidencias disponibles y orientar a los cirujanos ortopédicos respecto a esta patología. El comportamiento de esta guía es dinámico, dadas las múltiples opiniones, experiencias y evidencias, que surgen diariamente, por lo que recomendamos mantenerlo como referencia, no como certeza.

A pandemic has been declared due to a new highly contagious virus called severe acute respiratory syndrome coronavirus 2 (SARS-CoV2). The world has come to a halt due to the rapid expansion of a virus whose lethality has reached $15 \%$ in some countries. In recibido

27 de abril de 2020

aceptado

21 de enero de 2021
DOI https://doi.org/

10.1055/s-0041-1728739. ISSN $0716-4548$.
(C) 2021. Sociedad Chilena de Ortopedia y Traumatologia. All rights reserved.

This is an open access article published by Thieme under the terms of the Creative Commons Attribution-NonDerivative-NonCommercial-License, permitting copying and reproduction so long as the original work is given appropriate credit. Contents may not be used for commercial purposes, or adapted, remixed, transformed or built upon. (https://creativecommons.org/ licenses/by-nc-nd/4.0/)

Thieme Revinter Publicações Ltda., Rua do Matoso 170, Rio de Janeiro, RJ, CEP 20270-135, Brazil 


\author{
Keywords \\ - pandemic \\ - covid-19 \\ - orthopedic surgery
}

Chile, the government has taken decisive, aggressive measures in an attempt to control disease spread and provide healthcare to those who need it. These decisions include the suspension of elective surgeries and other ambulatory procedures. As Orthopedic surgeons we have been affected by these measures and there is doubt regarding the best course of action. We prepared this guide to summarize available evidence and orient our colleagues regarding this pathology. This guide is meant to be dynamic, as new opinions, evidence and experiences arise every day. Therefore, we advise the reader to keep it as a reference, not an undisputable truth.

\section{Introducción}

El 12 de marzo de 2020, la Organización Mundial de la Salud (OMS) declaró una pandemia ante la propagación de un nuevo virus con alta contagiosidad, proveniente de China, llamado síndrome respiratorio agudo severo coronavirus 2 (severe acute respiratory syndrome coronavirus 2 , SARS-CoV2).

Quisimos hacer esta guía para resumir parte de la evidencia disponible y orientar a los cirujanos ortopédicos respecto a esta patología. El comportamiento de esta guía es dinámico, porque hay múltiples estudios, opiniones y experiencias diariamente, por lo que recomendamos mantenerlo como referencia, no como certeza. Esperamos ir actualizándola de manera continua, según necesidad.

\section{¿Qué es Covid-19?}

Durante diciembre de 2019, aparecieron 41 casos de neumonía de etiología desconocida en Wuhan, China, que es un importante centro de transporte. La mayoría de estos pacientes reconocen haber visitado un mercado local de peces y animales salvajes durante el mes previo a la aparición de éstos casos.

El virus se contrae a través de las vías respiratorias, principalmente a través de gotitas de Flügge y contacto con superficies contaminadas. ${ }^{1}$ Los síntomas más frecuentes son fiebre y tos (-Tabla $\mathbf{1}$ ), pero existen pacientes que pueden debutar afebriles.

El diagnóstico se realiza con reacción en cadena de polimerasa en tiempo real (real-time polymerase chain reaction, RT-PCR), con una sensibilidad del 61\% al $70 \%$ durante la primera semana de síntomas. Desde el día 8 al 14 , la sensibilidad de esta prueba en hisopado orofaríngeo (HOF) baja del $61 \%$ al $50 \%{ }^{\circ}$ en casos severos, y es de un $29 \%$ si la sintomatología es leve. ${ }^{2}$

Dadas las múltiples ofertas de pruebas de detección que se han expandido en el mundo hasta la fecha de este reporte, sea de muestras de vías aéreas o muestras de sangre, la Sociedad Chilena de Infectología ha elaborado una revisión en la que se aclara la utilidad de las diferentes pruebas (-Tabla 2 ). ${ }^{2}$

Está demostrado que las mayores tasas de mortalidad se presentan en pacientes con comorbilidad ( - Tabla 3 ) Este virus provoca dos tipos de síndromes en pacientes en que se manifiesta en su forma más grave: uno se comporta como una tormenta de citoquinas, y el otro, como un síndrome antifosfolipidos. Existen signos que nos indican que el paciente está evolucionando de manera inadecuada, mencionados en la - Tabla 4.

\section{Tratamiento}

El único tratamiento probado en contra de la enfermedad por coronavirus 2019 (coronavirus disease 2019, Covid-19) son medidas de soporte; esto va desde mantener a un paciente con un caso leve en la casa bien hidratado, hasta el uso de ventilación mecánica y manejo general del distress respiratorio.

Desde el punto de vista de traumatología y ortopedia, se ha descrito previamente aumento de morbimortalidad en pacientes con neumonía y fractura de cadera. ${ }^{3}$ De la misma forma, existe una tasa de complicaciones pulmonares postquirúrgicas de un $5 \%$ luego de un tratamiento quirúrgico de fractura de cadera. De una serie ${ }^{4}$ de 10 pacientes con fractura mayor y infectados con Covid-19, 4 fallecieron entre 8 a 11 días desde su admisión en Urgencias, de los cuales sólo 1 fue intervenido a la brevedad, con consiguiente muerte precoz. Estos pacientes presentaron neutrocitosis, linfopenia y aumento

Tabla 1 Síntomas de Covid-19

\begin{tabular}{|l|l|l|}
\hline Síntomas & $\begin{array}{l}\text { Frecuencia } \\
\text { (porcentaje) }\end{array}$ & Autores \\
\hline Fiebre & $83-100$ & 1,2 \\
\hline Tos & $61-90$ & 1,2 \\
\hline Fatiga & $27-100$ & 1,3 \\
\hline Expectoración & 21 & 1 \\
\hline Mialgias, artralgias & $14-50$ & ${ }^{1,3}(76)$ \\
\hline $\begin{array}{l}\text { Síntomas gastrointestinales } \\
\text { (diarrea) }\end{array}$ & 10 & ${ }^{1}(77)$ \\
\hline Disnea & $12-14$ & 1 \\
\hline Odinofagia & 8 & 1 \\
\hline $\begin{array}{l}\text { Cefalea, mareos, } \\
\text { compromiso de consciencia }\end{array}$ & 9 & ${ }^{1}(70)$ \\
\hline $\begin{array}{l}\text { Síntomas del tracto respiratorio } \\
\text { superior (rinorrea, anosmia) }\end{array}$ & 5 & ${ }^{1}(69)$ \\
\hline Falla multiorgánica & 6 & ${ }^{1}(75)$ \\
\hline Hepato o esplenomegalia & & ${ }^{4}(75)$ \\
\hline Encefalitis & & 5 \\
\hline
\end{tabular}


Tabla 2 Pruebas diagnósticas utilizadas en el estudio de Covid-19

\begin{tabular}{|l|l|l|l|}
\hline & Detección & Valor & Beneficiados \\
\hline $\begin{array}{l}\text { Técnicas de amplificación } \\
\text { de ácido ribonucleico (ARN) }\end{array}$ & $\begin{array}{l}\text { Infección actual. } \\
\text { Toma de muestra } \\
\text { respiratoria } \\
\text { de hisopado } \\
\text { orofaríngeo } \\
\text { (HOF) }\end{array}$ & $\begin{array}{l}\text { - Informa el estado de infección } \\
\text { individual, ayuda a anticiparse y a } \\
\text { tomar medidas de prevención } \\
\text { de propagación }\end{array}$ & $\begin{array}{l}\text { - Pacientes } \\
\text { - Instituciones de salud } \\
\text { - Salud Ppública }\end{array}$ \\
\hline Detección de anticuerpos & $\begin{array}{l}\text { Infección en curso } \\
\text { o previa }\end{array}$ & $\begin{array}{l}\text { - Detecta los previamente infectados } \\
\text { y los susceptibles } \\
\text { - Identifica a los que poseen } \\
\text { anticuerpos neutralizantes } \\
\text { - Permite el seguimiento de contactos }\end{array}$ & $\begin{array}{l}\text { - Sujetos potencialmente } \\
\text { inmunes } \\
\text { - Instituciones de salud } \\
\text { - Salud pública }\end{array}$ \\
\hline Detección de antígenos & Infección actual & $\begin{array}{l}\text { - Podría informar el estado de infección } \\
\text { actual. Falta información suficiente }\end{array}$ & $\begin{array}{l}\text { - Pacientes } \\
\text { - Instituciones de salud }\end{array}$ \\
\hline
\end{tabular}

Tabla 3 Comorbilidades y su impacto en la mortalidad de Covid-19

\begin{tabular}{|l|l|l|}
\hline Comorbilidad & $\begin{array}{l}\text { Riesgo de } \\
\text { mortalidad } \\
\text { (porcentaje) }\end{array}$ & Autor \\
\hline$>60$ años & 80 & 1 \\
\hline$>50$ años & 90 & 1,6 \\
\hline Patología cardiovascular & $10.5-13.2$ & 1,6 \\
\hline Hipertensión & $8.3-65.9$ & $1,6,7$ \\
\hline $\begin{array}{l}\text { Diabetes con hemoglobina } \\
\text { glicada (A1c) }>7.6 m g \%\end{array}$ & $7.3-9.2$ & 1,6 \\
\hline Patología respiratoria & $8.0-10.3$ & 1,6 \\
\hline Cáncer & $5.6-7.6$ & 1,6 \\
\hline Sin comorbilidades & $0.9-1.4$ & 1 \\
\hline Uso de terapia biológica** & & ${ }^{*}(76)$ \\
\hline Trasplante o mesenquimopatia** & & $6(76)$ \\
\hline HIV con células CD4 $<200^{*}$ & & 6 \\
\hline
\end{tabular}

Notas: *De los pacientes que han muerto, porcentaje de riesgo. **Teórico.

Tabla 4 Signos de mal pronóstico ${ }^{13}$

\begin{tabular}{|l|l|}
\hline En signos vitales & En laboratorio \\
\hline $\begin{array}{l}\text { Frecuencia respiratoria } \\
>24 / \text { minuto }\end{array}$ & Dímero D $>1.000 \mathrm{ng} / \mathrm{mL}$ \\
\hline $\begin{array}{l}\text { Frecuencia cardíaca } \\
>125 / \text { minuto }\end{array}$ & $\begin{array}{l}\text { Creatina quinasa mayor al } \\
\text { doble de lo normal }\end{array}$ \\
\hline $\begin{array}{l}\mathrm{SpO}_{2}<93 \% \text { con } \\
\mathrm{FiO}_{2} \text { ambiental }\end{array}$ & Proteína C-reactiva $>100$ \\
\hline $\mathrm{PaO}_{2} / \mathrm{FiO}_{2}<300 \mathrm{~mm} \mathrm{Hg}$ & $\begin{array}{l}\text { Lactato deshidrogenasa } \\
\end{array}$ \\
\hline & Tropinina elevada $/ \mathrm{L}$ \\
\hline & $\begin{array}{l}\text { Recuento total de } \\
\text { linfocitos }<0.8\end{array}$ \\
\hline & Ferritina $>500 \mathrm{U} / \mathrm{L}$ \\
\hline
\end{tabular}

Abreviaturas: $\mathrm{FiO}_{2}$, fracción inspirada de oxígeno; $\mathrm{PaO}_{2}$, presión parcial de oxígeno en sangre arterial; $\mathrm{SpO}_{2}$, saturación de oxígeno.
Tabla 5 Medidas para evitar el contagio

\begin{tabular}{|l|l|l|}
\hline Medida & Cuando & Autores \\
\hline Lavado de manos & Siempre & 1,13 \\
\hline Uso de mascarillas & Siempre & 1,13 \\
\hline $\begin{array}{l}\text { Distanciamento social } \\
\text { (más de 1 metro) }\end{array}$ & Siempre & 1,13 \\
\hline $\begin{array}{l}\text { Equipos de protección } \\
\text { personal }\end{array}$ & $\begin{array}{l}\text { Personal } \\
\text { de salud }\end{array}$ & 13 \\
\hline Cuarentena de 14 días & Contacto & 1 \\
\hline $\begin{array}{l}\text { Guantes, cubrir la cara, } \\
\text { cambiar la ropa }\end{array}$ & Siempre & 13 \\
\hline $\begin{array}{l}\text { Cierre de lugares públicos } \\
\text { (centros comerciales, colegios) }\end{array}$ & Caso a caso & 1 \\
\hline Cierre del transporte público & Caso a caso & 1 \\
\hline Cierre de lugares de trabajo & Caso a caso & 1 \\
\hline Cuarentena total & Caso a caso & 1 \\
\hline Cierre de fronteras & Etapa IV & 1 \\
\hline
\end{tabular}

de dímero D más acentuados que pacientes sin fractura, lo que se correlaciona con mayor gravedad del cuadro. ${ }^{4}$

\section{Normas de control}

Es necesario tomar todas las medidas necesarias para evitar estos grados de contagio (-Tabla 5). La cuarentena de los contactos debe ser a los 14 días, porque, a los 12 días, $98 \%$ de los pacientes ya está sintomático, como lo explicamos previamente.

\section{Los tres conceptos clave}

1. Urgencia clínica;

2. Protección al paciente y al trabajador de la salud; y

3. Conservación de los recursos en salud. ${ }^{5}$

En una pandemia en la etapa IV, como cirujanos ortopédicos, estamos expuestos a diferentes mecanismos de contagio. En España, el $14 \%$ de los contagios correspondía a personal de salud. En Wuhan, China, entre diciembre de 2019 y febrero 
2020, los traumatólogos reportaron un promedio de 5,6\% de incidencia de contagios por SARS-CoV2 repartidos en sus 8 hospitales, y los lugares de sospecha más frecuentes de contagio fueron en salas de espera (79\%), lugares públicos del hospital (20,8\%), y pabellones quirúrgicos (12,5\%). Uno de cada cuatro de ellos sufrió contagio directo de otro colega del grupo.,

Para disminuir el riesgo de contagio intrahospitalario e infección cruzada, es fundamental el uso obligatorio de equipo de protección personal (personal protective equipment, PPE), que incluye batas, guantes, mascarillas y respiradores N95, P100, FFP2, con gafas o respirador con poder purificador de aire (PARP). También se recomiendan lavado de manos meticuloso y desinfección de artículos personales como estetoscopio, teléfonos celulares, laptops, etc. ( - Tabla 6).

\section{Como distribuir unidades de cirugía ortopédica}

Se deben crear equipos, los cuales deben estar absolutamente aislados unos de otros. ${ }^{8}$ El ideal es crear equipos con al menos 12 días de separación entre ellos, ${ }^{9}$ o 2 semanas, para resolver lo mínimo en el servicio. Debe haber equipos para atender pacientes positivos para el Covid-19 y equipos para atender

Tabla 6 Recomendaciones de equipo de protección personal (EPP) para diferentes actividades y lugares al enfrentarse a paciente confirmado/sospechoso de infección por SARS-CoV2

\begin{tabular}{|c|c|c|}
\hline Lugar & Mecanismo & Grupos de estudio involucrados \\
\hline Triaje & Triaje y examinación inicial & $\begin{array}{l}\text { 1. Máscara quirúrgica } \\
\text { 2. Bata regular AAMI nivel II } \\
\text { 3. Gafas o escudos faciales } \\
\text { 4. Guantes } \\
\text { 5. Higiene de manos antes y después de examinar cada paciente }\end{array}$ \\
\hline $\begin{array}{l}\text { Consulta médica } \\
\text { ambulatoria } 1\end{array}$ & $\begin{array}{l}\text { Examinación de paciente Covid-19 (-), sin signos } \\
\text { respiratorios }\end{array}$ & $\begin{array}{l}\text { 1. Máscara quirúrgica } \\
\text { 2. Guantes } \\
\text { 3. Atención a la contaminación ambiental (herramientas, artículos } \\
\text { de trabajo) } \\
\text { 4. Higiene de manos antes y después de examinar cada paciente }\end{array}$ \\
\hline $\begin{array}{l}\text { Consulta médica } \\
\text { ambulatoria } 2\end{array}$ & $\begin{array}{l}\text { Examinación de paciente Covid-19 }(+) \text {, o con fiebre } \\
\text { y/o signos respiratorios }\end{array}$ & $\begin{array}{l}\text { 1. Máscara N95 certificada NIOSH ajustada (si está disponible) o } \\
\text { máscara quirúrgica (considere técnica de máscara } \\
\text { doble/múltiple y asegúrese de un ajuste perfecto) } \\
\text { 2. Bata regular AAMI nivel II } \\
\text { 3. Gafas o escudos faciales } \\
\text { 4. Guantes (considere doble guante) } \\
\text { 5. Higiene de manos antes y después de examinar cada paciente }\end{array}$ \\
\hline $\begin{array}{l}\text { Box de } \\
\text { procedimientos }\end{array}$ & $\begin{array}{l}\text { Efectuar cuidados no invasivos para paciente Covid- } \\
19(+) \text {, o con fiebre y/o signos respiratorios }\end{array}$ & $\begin{array}{l}\text { 1. Máscara N95 certificada NIOSH ajustada (si está disponible) o } \\
\text { máscara quirúrgica (considere técnica de máscara } \\
\text { doble/múltiple y asegúrese de un ajuste perfecto) } \\
\text { 2. Bata regular AAMI nivel II } \\
\text { 3. Gafas o escudos faciales } \\
\text { 4. Guantes (considere doble guante) } \\
\text { 5. Higiene de manos antes y después de examinar cada paciente }\end{array}$ \\
\hline $\begin{array}{l}\text { Sala de } \\
\text { preanestesia }\end{array}$ & $\begin{array}{l}\text { Evitar contacto innecesario de ortopedista con } \\
\text { paciente. Protección para anestesista en caso de } \\
\text { procedimiento productor de aerosoles }\end{array}$ & $\begin{array}{l}\text { 1. Respiradores purificadores de aire (PAPRs, Powered Air-purifing } \\
\text { Respirators), si están disponibles, o } \\
\text { 2. Máscara N95 certificada NIOSH ajustada } \\
\text { 3. Protección para los ojos: gafas (lados de ojos cubiertos) o } \\
\text { protectores faciales } \\
\text { 4. Bata quirúrgica desechable AAMI nivel III } \\
\text { 5. Guantes quirúrgicos dobles con puños altos (alternativamente, } \\
\text { las tiras verticales de cinta pueden mantener los guantes } \\
\text { asegurados a la bata) } \\
\text { 6. Los zapatos usados deben ser resistentes a los fluidos y fáciles de } \\
\text { ser descontaminados (fundas de zapatos desechables podrían } \\
\text { aumentar el riesgo de contaminación) } \\
\text { 7. Higiene de manos antes y después de ponerse/quitarse el EPP } \\
\text { 8. Una ducha después de la generación de aerosoles respiratorios }\end{array}$ \\
\hline $\begin{array}{l}\text { Quirófano/ } \\
\text { Pabellón } 1\end{array}$ & $\begin{array}{l}\text { Cirugía de urgencia, control de daños, minimizando } \\
\text { riesgo y tiempo quirúrgico en paciente Covid-19 } \\
\text { (+), o con fiebre y/o signos respiratorios } \\
\text { (pabellón no generador de aerosoles) }\end{array}$ & $\begin{array}{l}\text { 1. PAPRs, si están disponibles, o } \\
\text { 2. Máscara N95 certificada NIOSH ajustada } \\
\text { 3. Protección para los ojos: gafas (lados de ojos cubiertos) o } \\
\text { protectores faciales } \\
\text { 4. Bata quirúrgica desechable AAMI nivel III } \\
\text { 5. Guantes quirúrgicos dobles con puños altos (alternativamente, } \\
\text { las tiras verticales de cinta pueden mantener los guantes } \\
\text { asegurados a la bata) } \\
\text { 6. Los zapatos usados deben ser resistentes a los fluidos y fáciles de } \\
\text { ser descontaminados (fundas de zapatos desechables podrían } \\
\text { aumentar el riesgo de contaminación) } \\
\text { 7. Higiene de manos antes y después de ponerse/quitarse el EPP }\end{array}$ \\
\hline
\end{tabular}


Tabla 6 (Continued)

\begin{tabular}{|l|l|l|}
\hline Lugar & Mecanismo & Grupos de estudio involucrados \\
\hline $\begin{array}{l}\text { Quirófano/ } \\
\text { Pabellón 2 }\end{array}$ & $\begin{array}{l}\text { Cirugía de urgencia generadora de aerosoles y } \\
\text { gotitas de sangre en paciente Covid-19 (+), o con } \\
\text { fiebre y/o signos respiratorios }\end{array}$ & $\begin{array}{l}\text { 1. PAPRs, si están disponibles, o } \\
\text { 2. Máscara N95 certificada NIOSH ajustada } \\
\text { 3. Protección para los ojos: gafas (lados de ojos cubiertos) o } \\
\text { protectores faciales } \\
\text { 4. Bata quirúrgica desechable AAMI nivel III } \\
\text { 5uantes quirúrgicos dobles con puños altos (alternativamente, } \\
\text { las tiras verticales de cinta pueden mantener los guantes } \\
\text { asegurados a la bata) }\end{array}$ \\
& $\begin{array}{l}\text { 6. Los zapatos usados deben ser resistentes a los fluidos y fáciles de } \\
\text { ser descontaminados (fundas de zapatos desechables podrían } \\
\text { aumentar el riesgo de contaminación) } \\
\text { 7. Higiene de manos antes y después de ponerse/quitarse el EPP } \\
\text { 8. Una ducha después de la generación de aerosoles respiratorios }\end{array}$ \\
\hline $\begin{array}{l}\text { Sala de } \\
\text { recuperación }\end{array}$ & Retiro del EPP & $\begin{array}{l}\text { 1. Especial atención en evitar autocontaminarse durante el retiro } \\
\text { de EPP }\end{array}$ \\
\hline
\end{tabular}

pacientes negativos. No se recomienda que los cirujanos trabajen más de seis horas seguidas, tanto para evitar exposición como para evitar fatiga. ${ }^{6}$

\section{Manejo de patología ortopédica en la Unidad de Emergencia}

Existen varias alternativas para pacientes traumatológicos que necesiten consultar en urgencia, desde un punto de vista "viral":

\section{Tipos de pacientes "virales" de consulta en Urgencia General}

1. Paciente con Covid-19 diagnosticado previamente.

2. Paciente con cuarentena preventiva por haber tenido contacto directo sujeto diagnosticado con Covid-19.

3. Paciente sin cuarentena sintomático.

4. Paciente sin cuarentena asintomático, pero dentro de perímetro de cuarentena total, por encontrarse en zona epidemiológicamente peligrosa de contacto no tratable.

5. Paciente sin cuarentena, asintomático, fuera de perímetro de cuarentena total.

En la fase IV, se ha determinado, bajo decreto ministerial y por recomendación mundial, ${ }^{10}$ la postergación de toda cirugía electiva posible, al igual que toda atención médica ambulatoria o urgente que no signifique poner en riesgo la vida del paciente o dejar secuela potencialmente grave. Debido a la fisiopatología de este virus en nuestro organismo, ${ }^{11}$ en el que afecta no sólo al epitelio alveolar sino que también renal, hepático, cerebro e intestino, ${ }^{12}$ este virus aumenta la morbimortalidad de pacientes con algún trauma, ${ }^{4}$ y más aun de los sometidos a una invasividad quirúrgica. El estrés asociado con una fractura y tratamiento quirúrgico puede gatillar una serie de cascada oxidativa y respuesta inflamatoria excesiva que disminuye la capacidad inmune del paciente, por lo que aumenta el daño pulmonar y sistémico del SARS-CoV2 y otros patógenos. ${ }^{3}$

Diferentes asociaciones de cirujanos y ortopedistas en el mundo recomiendan medidas en relación a atención de paciente traumatológico en Urgencias ${ }^{10,13,14}$ por la pandemia de Covid-19.

El siguiente es un resumen de las medidas recomendadas para la atención de paciente traumatológico en Urgencias por la pandemia de Covid-19.

1. Dotación de personal. Debe reducirse al máximo la presencia de personal en todos niveles.

2. Evitar la presencia de materiales de trabajo no esenciales.

3. Disponer de dispensadores de capas protectoras, cubrecalzado y mascarilla protectora segura y efectiva, al igual que receptáculos de éstos al desecharlos. Todo lo utilizado con el paciente debe ser desechado de forma inmediata al terminar la atención.

4. Minimizar la indicación de imágenes para evitar el traslado de pacientes al servicio de imágenes.

5. Se debe evitar el tráfico de personal de entrada y salida al box de traumatología de Covid-19.

6. Realizar procedimientos de reparación de partes blandas resolutivos.

7. Una vez terminada la atención, mantener resguardo del paciente para evitar su deambulación fuera del box. En caso de fractura mayor (de columna, fémur) o fractura expuesta que requiera hospitalización y/o manejo quirúrgico, se recomienda ingresar con una tomografía axial computarizada (TAC) de tórax, pues el resultado del estudio de Covid-19 puede demorar. En un estudio reciente $^{4}$ en el que se evaluaron pacientes con fractura mayor y Covid-19, llama la atención que 3 de ellos presentaron resultado negativo para Covid-19 en el RTPCR al ingreso, y se confirmó su diagnóstico mediante $\mathrm{TAC}$, en la que se encontraraon hallazgos sugerentes de neumonía por SARS-CoV2. ${ }^{4,15}$

8. En caso de alta ambulatoria, citar de manera vigilada a consultorio de la especialidad habilitado especialmente para dos situaciones: pacientes traumatológicos infectados o con sospecha de Covid-19, y otro para pacientes sin sospecha. $\mathrm{Si}$ es posible, realizar telemedicina para control.

Para el resto de los pacientes traumatológicos, con poca sospecha de Covid-19, disponer de pruebas rápidas para el 
descarte de Covid-19 en 10 a 15 minutos, dado el alto porcentaje (25\% a 50\%) de pacientes asintomáticos. Si requiere tomarse imágenes para estudio traumatológico, solicitar radiografía de tórax complementaria. ${ }^{13}$

Especial mención para el paciente politraumatizado grave, que debe disponer de igual manera de su sala de reanimación o atención aguda con todas las medidas de higiene y protección para el personal del equipo de trauma. Ante el contexto epidemiológico, debe considerarse a todo paciente de estas características como potencialmente infectado. ${ }^{13}$

\section{Paciente de traumatología pediátrica de urgencia}

Para los casos pediátricos, se debe resguardar similares recomendaciones previamente señaladas; sin embargo, la biología musculoesquelética en los niños nos permite tejer algunas consideraciones: ${ }^{14,16}$

Si es posible, las siguientes sospechas diagnósticas pueden ser tratadas sin radiología:

(a) Lesiones de tejidos blandos.

(b) Fracturas de muñeca, escafoides, antebrazo, clavícula y humerales proximales.

(c) Fracturas de huesos largos con deformidad clínica.

(d) Fracturas de pie sin deformidad clínica e hinchazón significativas.

\section{Las siguientes lesiones pueden tratarse sin yeso (con inmovilización removible)}

(a) Lesión ligamentaria de la rodilla y lesiones rotulianas simples.

(b) Fracturas de tobillo estables.

(c) Lesiones del retropié, el mediopié y el antepié.

Un control ambulatorio único a las 4 a 12 semanas, dependiendo de la extremidad o el hueso fracturado, es aceptable para la mayoría de las lesiones. El seguimiento estricto inicial con radiografías a las 2 semanas, y posterior teleconferencia a las 4 a 6 semanas, es apropiado para las siguientes condiciones:

(a) Subluxaciones y dislocaciones rotulianas, lesión de ligamentos de la rodilla, y lesiones meniscales, excluidas las rodillas bloqueadas.

(b) Fracturas maleolares laterales y posibles fracturas por avulsión del tobillo.

(c) Lesiones en los pies, excepto sospechas de lesiones en la parte media y posterior del pie.

(d) Fracturas de muñeca desplazadas reducidas en pabellón, antebrazo, clavícula y humerales, incluido el húmero proximal.

(e) Fracturas supracondíleas Gartland tipos 2 y 3, que requirieron reducción con anestesia.

Lesiones de manejo definitivo con yeso desde urgencias, para eventual retiro desde el hogar, y posterior teleconferencia a las 4 a 6 semanas

(a) Fracturas de tobillo sin compromiso neurovascular o de tejidos blandos (Salter Harris 2, fractura triplanar, fractura de Tillaux). Un pequeño número de estos pacientes puede requir intervención:

- Admita al paciente si existe un alto riesgo de síndrome compartimental (lesiones en adolescentes o de alta energía).

- Considere la sedación para reducir la deformidad clínicamente importante.

- Acepte que la deformidad residual, el compromiso articular, o la unión defectuosa pueden requerir cirugía correctiva.

(b) Fracturas de muñeca desplazadas reducidas en box de urgencias, en niños menores de diez años.

(c) Fracturas de tobillo y antebrazo no desplazadas.

(d) Fracturas supracondileas Gartland tipo 2, no desplazadas

(e) Fracturas de clavícula

(f) Fractura de condilo lateral no desplazada

Todas las recomendaciones mencionadas previamente deben ser muy consensuadas en su centro asistencial, de manera de coordinar y unificar el manejo de todos los pacientes adultos y pediátricos, de acuerdo con la realidad epidemiológica, infecciosa y asistencial local.

\section{Realización de cirugías durante esta etapa}

Para empezar, recomendamos revisar los consentimientos informados y agregar la información respecto a Covid-19. ${ }^{9} \mathrm{Se}$ sugiere asumir todos los pacientes como portadores asintomáticos. Esto se debe a que los distintos exámenes han mostrado sensibilidad variable desde un $77 \%$ a $92 \%$, incluso con casos de pacientes con exámenes repetidos negativos e infección severa. ${ }^{17-19}$

\section{¿Cómo manejar el pabellón en casos de pacientes Covid-19, confirmados o sospechosos?}

Dada la gran cantidad de aerosoles, el principal mecanismo de contagio de SARS-Cov2, ${ }^{20}$ es ideal contar con pabellones con presión negativa, sobretodo en cirugía con sedación por gases o anestesia general. Hasta ahora, hay pocos reportes, principalmente dos, ${ }^{21,22}$ uno donde utilizan presión negativa en fase de inducción anestésica y otro en pacientes con cáncer de colón que lo usan durante toda la cirugía. No se recomienda el uso de flujo laminar. ${ }^{23}$

Se describe que es necesario mantener al menos tres filtros entre el paciente y el personal de pabellón. (escafandra, mascara al personal y mascarilla al paciente hasta la intubación, por ejemplo).

Los PPE deben incluir mascarilla con filtros N95 o similar (FPP2 o FPP3), protección ocular, guantes, delantal desechable, balaclava azul, ${ }^{23}$ y cubrecalzado ${ }^{24-26}$; lo ideal es incluir un escudo facial (face shield) ${ }^{23}$ (Tabla 6). No está indicado el uso de trajes con $\operatorname{casco}^{23}$ porque, una vez aerolizado, el motor del casco va a trasmitir las gotitas infectadas dentro del traje, y esto puede hasta aumentar la carga viral. 
Durante la cirugía, evitar todas las situaciones que producen aerolización; dos recomendaciones específicas: usar el electrobisturí cubierto con aspiración (se corta la parte azul del tubo de aspiración, se hace una ranura en la parte trasparente con un bisturí, y se pasa la punta del electrobisturí por ahí; esto permite que el humo [que aeroliza el virus], vaya siendo aspirado al mismo tiempo en que se corta), y no usar lavado pulsatil. ${ }^{23}$ Además, cuidado al fresar; dentro de lo posible, usar fresado manual, que produce menos dispersión de sangre y aerolización de la misma. $^{23}$

Dentro de lo posible, usar suturas reabsorbibles y cubrir las heridas con plásticos trasparentes (como Tegaderm [3M, Saint Paul, Minnesota, EEUU]), para poder observar las heridas sin tener que descubrirlas y minimizar el contacto con el paciente en el ambulatorio ${ }^{23}$ (sirve para monitorizar también las heridas por telemedicina).

Se recomienda que el anestesiólogo se mantenga solo con el paciente dentro del pabellón; el auxiliar de anestesia es innecesario. La pabellonera no debe nunca contactarse con la arsenalera, solo debe dejar caer el material en la mesa estéril. ${ }^{9}$ Todo el mundo debe mantenerse dentro del pabellón hasta que el paciente salga de éste; luego, deben retirarse los EPP dentro del pabellón de la manera adecuada (-Fig. 1). ${ }^{22}$

\section{¿Qué cirugías son las ideales a realizar en este período?}

Urgencias vitales $\mathrm{y} / \mathrm{o}$ con riesgo de secuela mayor (amputación, para/cuadraplejía).

- Mano/Pie gravemente lesionada(o).

- Síndrome compartimental.

- Fractura inestable de pelvis con compromiso hemodinámico actual o inminente.

- Trauma raquimedular con compromiso neurológico.

- Tumores con fractura inminente de huesos largos y/o raquídea con compromiso neurológico actual o inminente.

- Síndrome de cauda equina.

- Luxación de articulaciones nativas o protésicas (reducción en box de urgencia).

- Fracturas con articulares con deformidad mayor, que impliquen compromiso neurológico y/o vascular, y que no mejoren tras reducción ortopédica e inmóvilización adecuada.

- Fracturas expuestas Gustilo III o equivalente.

- Fractura de fémur en menor de 45 años.

- Abscesos sin compromiso séptico: drenar en urgencias

- Artritis infecciosa con compromiso sistémico (sepsis formal): pabellón mayor.

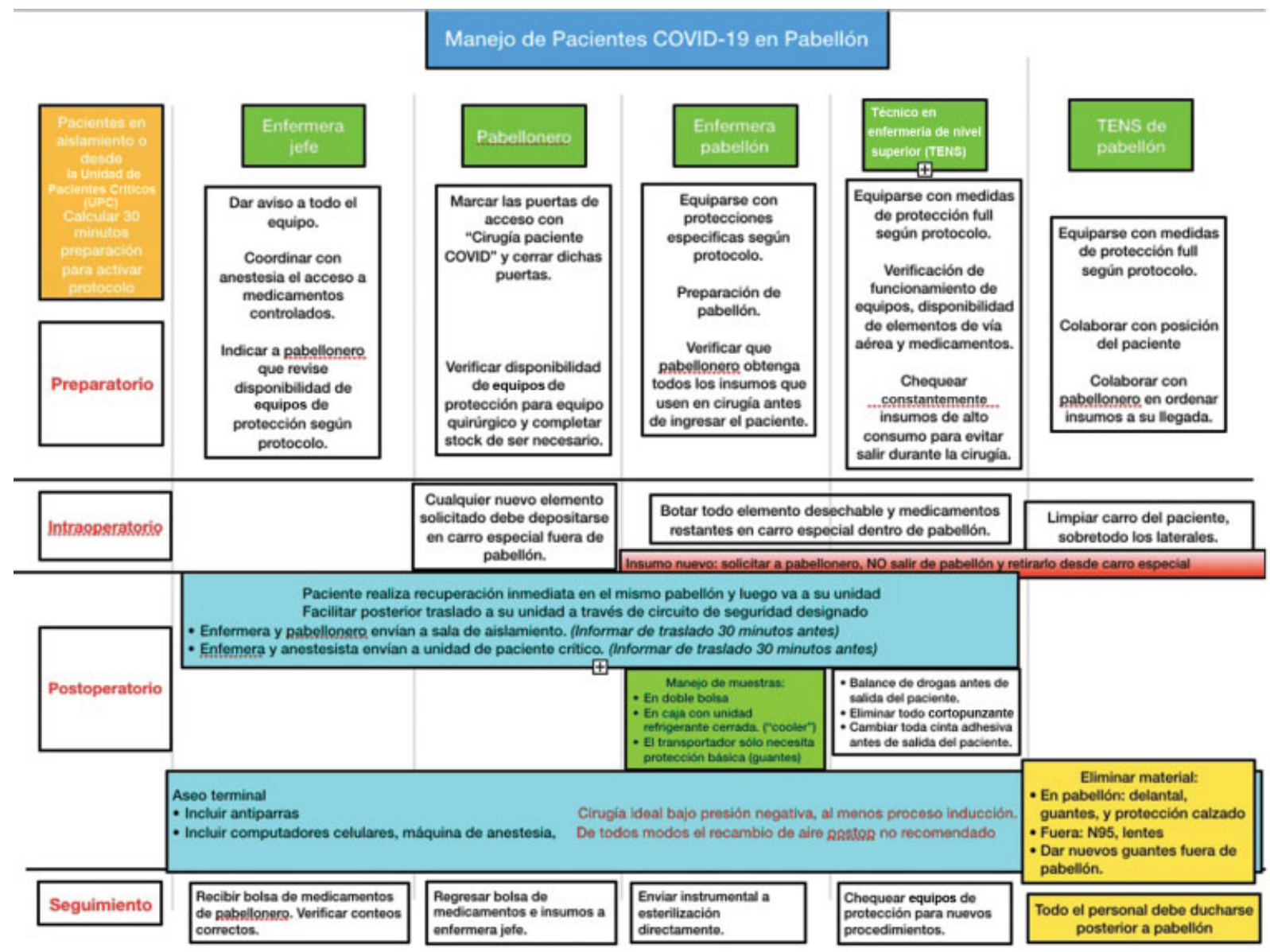

Fig. 1 Manejo de pacientes con Covid-19 en pabellón. 
- Lesiones traumáticas sin fracturas con lesión neurovascular.

- Lesiones traumáticas abiertas sin fracturas con lesión tendínea aguda o subaguda.

- Paciente con reemplazo articular previo que presente fiebre, o requiera drenaje de herida.

\section{Urgencias diferibles}

- Fracturas expuestas Gustilo I-II o equivalente.

- Fractura de cadera en adulto mayor: deben ser resueltas antes de 48 a 72 horas

- Fracturas de huesos largos de las extremidades inferiores: pilón tibial, y platillos tibiales Schatzker IV a VI. Resolución en un tiempo quirúrgico, considerar fijador externo como cirugía definitiva en caso de utilizarlo.

- Mielopatía cervicoartrósica de instalación rápidamente progresiva.

- Radiculopatía invalidante con compromiso motor M3 o menor.

- Paciente con indicación de reemplazo articular que presente exacerbación de dolor.

- Fractura vertebral compresiva, excepto aquellas de manejo ortopédico.

- Infección en columna.

- Cifosis de la unión proximal sintomática.

- Escoliosis asociado a déficit neurológico.

\section{Diferible con opción de invalidez que pueda ser candidata a reconstrucción compleja}

- Fracturas no descritas en apartados previos con desplazamientos que no impliquen riesgo de exposición, compromiso neurológico ni vascular tras reducción

- Lesiones ligamentarias de rodilla que no impliquen luxación formal de la misma.

\section{No urgente}

- Toda otra patología ortopédica fuera de lo descrito.

Las hospitalizaciones deben reducirse al máximo, con una estadía menor a 23 horas; los pacientes deben ser operados lo antes posible. ${ }^{27}$

\section{Reintroducción de la cirugía electiva}

Para retomar cirugías electivas, recomendamos:

1. Al menos catorce días de curva de contagios descendiente.

2. Protocolos claros, institucionalizados, y control del cumplimiento de estos.

3. Triage: Priorizar lo más grave y más urgente.

4. Considerar testeo obligatorio a todos los pacientes que deban ser sometidos a cirugía, considerando el alto porcentaje de falsos negativos (30\%). El triaje debe contemplar dos pruebas.

5. No relajar las medias de protección personal.

6. Considerar la capacidad de camas críticas del centro hospitalario donde se van a iniciar cirugías.

7. Considerar si las unidades de apoyo están disponibles. Estas pueden haber sido cerradas por problemas de personal, problemas económicos, o contaminación.
8. Estado psicológico del personal que va a trabajar en la reapertura.

9. No disminuir la calidad de la atención. ${ }^{28}$

\section{Conclusiones}

1. Minimizar el contacto con el paciente, sea en el ambulatorio, o en un contexto de urgencia o cirugía.

2. Ser muy estricto con las medidas de protección personal.

3. No operar nada que no sea estrictamente urgente.

4. Mantener la comunicación y cohesión de los equipos médicos; esto incluye los médicos en etapa de formación.

5. Prepararse para atención de urgencia.

6. No difundir información que no esté confirmada.

7. Centralizar las decisiones y algoritmo de funcionamiento en los grupos de jefatura.

Contribuciones de los autores

El presente artículo fue aprobado por todos los autores suscritos:

Karen Weissmann: concepción del trabajo, boceto del manuscrito, revisión y aprobación de la versión final para publicación.

Carlos Huaiquilaf: boceto del manuscrito, revisión y aprobación de la versión final para publicación.

Marcelo Costa: boceto del manuscrito, revisión y aprobación de la versión final para publicación.

Cristian Correa: boceto del manuscrito, revisión y aprobación de la versión final para publicación.

Alan Bey: boceto del manuscrito.

Luis Bahamondes: boceto del manuscrito, revisión y aprobación de la versión final para publicación.

Conflicto de Intereses

Los autores declaran no haber conflicto de intereses.

\section{Referencias}

1 Vannabouathong CDT, Ekhtiari S, Chang Y, et al.The Orthopedic Forum. Novel Coronavirus Covid-19: Current evidence and Evolving Strategies. JBJS 2020Express

2 Chanqueo LHJ, Legarraga $\mathrm{P}$, Moreno $\mathrm{V}$, et al. DIAGNÓSTICO MICROBIOLÓGICO DE SARS-CoV-2 (COVID-19) v1.0 In: Sochinf. CdMC-S, editor. http://www.sochinf.cl/portal/templates/sochinf 2008 /documentos/2020/Diagnostico_de_laboratorio_COVID19_SOCHINF. pdf?fbclid=IwAROP4LXUJ8nHAKM-oo9xmR6oepXhl59XSFIQWd-WP ip3A_lk2ffZao4TcWE2020

$3 \mathrm{Lv} \mathrm{H}$, Yin P, Long A, et al. Clinical characteristics and risk factors of postoperative pneumonia after hip fracture surgery: a prospective cohort study. Osteoporos Int 2016;27(10):3001-3009

4 Mi B, Chen L, Xiong Y, Xue H, Zhou W, Liu G. Characteristics and Early Prognosis of COVID-19 Infection in Fracture Patients. J Bone Joint Surg Am 2020;102(09):750-758

5 Chang Liang Z, Wang W, Murphy D, Po Hui JH. Novel Coronavirus and Orthopaedic Surgery: Early Experiences from Singapore. J Bone Joint Surg Am 2020;102(09):745-749

6 Guo X, Wang J, Hu D, et al. Survey of COVID-19 Disease Among Orthopaedic Surgeons in Wuhan, People's Republic of China. J Bone Joint Surg Am 2020;102(10):847-854

7 Chen G, Wu D, Guo W, et al. Clinical and immunologic features in severe and moderate forms of Coronavirus Disease 2019. Medrxiv 2020

8 COVIDSurg C. Global guidance for surgical care during the COVID19 pandemic. Br J Surg 2020;107(09):1097-1103 
9 Pahys JSP, Bas T, Brayda SD, et al. SRS Covid-19 Webinar. Scolisois Res Soc 2020

10 Mary B, Gawande A. Managing COVID-19 in Surgical Systems. Ann Surg 2020

11 Li G, Fan Y, Lai Y, et al. Coronavirus infections and immune responses. J Med Virol 2020;92(04):424-432

12 Zhang C, Shi L, Wang FS. Liver injury in COVID-19: management and challenges. Lancet Gastroenterol Hepatol 2020;5(05):428-430

13 ciujanos A. RECOMENDACIONES GENERALES DE ATENCION DE LA PATOLOGIA QUIRURGICA URGENTE EN EL CONTEXTO DE LA PANDEMIA POR COVID-19(SARS COV-2): www.aecirujanos.es2020

14 Management of patients with urgent orthopaedic conditions and trauma during the coronavirus pandemic. 2020

15 Abdelaziz MH, Abdelwahab SF, Wan J, et al. Alternatively activated macrophages; a double-edged sword in allergic asthma. J Trans Med 2020;18(01):58

16 Farrell S, Schaeffer EK, Mulpuri K. Recommendations for the Care of Pediatric Orthopaedic Patients During the COVID-19 Pandemic. J Am Acad Orthop Surg 2020;28(11):e477-e486

17 Chen Z, Li Y, Wu B, Hou Y, Bao J, Deng X. A Patient with COVID-19 Presenting a False-Negative Reverse Transcriptase Polymerase Chain Reaction Result. Korean J Radiol 2020;21(05):623-624

18 Guo L, Ren L, Yang S, et al. Profiling Early Humoral Response to Diagnose Novel Coronavirus Disease (COVID-19). Clin Infect Dis 2020;71(15):778-785

19 To KK, Tsang OT, Leung WS, et al. Temporal profiles of viral load in posterior oropharyngeal saliva samples and serum antibody responses during infection by SARS-CoV-2: an observational cohort study. Lancet Infect Dis 2020;20(05):565-574

20 Wang J, Du G. COVID-19 may transmit through aerosol. Ir J Med Sci 2020;189(04):1143-1144

21 Luo Y, Zhong M. [Standardized diagnosis and treatment of colorectal cancer during the outbreak of corona virus disease 2019 in Renji hospital]. Zhonghua Wei Chang Wai Ke Za Zhi 2020; 23(03):211-216

22 Ti LK, Ang LS, Foong TW, Ng BSW. What we do when a COVID-19 patient needs an operation: operating room preparation and guidance. Can J Anaesth 2020;67(06):756-758

23 COVID-19-Evidence based best practice guidelines specifi to orthopedic surgeons. 2020

24 Iacobucci G. Covid-19: Lack of PPE in care homes is risking spread of virus, leaders warn. BMJ 2020;368:m1280

25 Kantor J. Behavioral considerations and impact on personal protective equipment use: Early lessons from the coronavirus (COVID-19) outbreak. J Am Acad Dermatol 2020

26 Sorbello M, El-Boghdadly K, Di Giacinto I, et al. The Italian coronavirus disease 2019 outbreak: recommendations from clinical practice. Anaesthesia 2020

27 Giorgi PD, Villa F, Gallazzi E, et al. The management of emergency spinal surgery during the COVID-19 pandemic in Italy. Bone Joint J 2020;102-B(06):671-676

28 Kogan M, Klein SE, Hannon CP, Nolte MT. Orthopaedic Education During the COVID-19 Pandemic. J Am Acad Orthop Surg 2020;28 (11):e456-e464 